\title{
Mathematical Modeling of the Transmission Dynamics of Syphilis Disease Using Differential Transformation Method
}

\author{
Mbachu Hope Ifeyinwa \\ Department of Statistics, Imo State University, Owerri, Nigeria
}

Email address:

ifyjoe100@yahoo.com

\section{To cite this article:}

Mbachu Hope Ifeyinwa. Mathematical Modeling of the Transmission Dynamics of Syphilis Disease Using Differential Transformation Method. Mathematical Modelling and Applications. Vol. 5, No. 2, 2020, pp. 47-54. doi: 10.11648/j.mma.20200502.11

Received: February 21, 2020; Accepted: March 9, 2020; Published: March 24, 2020

\begin{abstract}
In this work, we developed a mathematical model for the transmission dynamics of the Syphilis disease under some assumptions made. The method of differential transformation is employed to compute an approximation to the solution of the non-linear systems of differential equations for the transmission dynamic of the disease model. The differential transformation method is a semi-analytic numerical method or technique, which depends on Taylor series and has application in many areas including Biomathematics. The disease-free equilibrium of the syphilis model is analyzed for local asymptotic stability and the associated epidemic basic reproduction number $\mathrm{R}_{0}$ is less than unity. It is also known that the global dynamics of the disease are completely determined by the basic reproduction number. Sensitivity analysis is performed on the model's parameters to investigate the most sensitive parameters in the dynamics of the disease, for control and eradication.
\end{abstract}

Keywords: Syphilis Disease, Differential Transformation Method, Transmission Dynamics, Endemic Equillibrium, Mathematical Modeling

\section{Introduction}

A mathematical model is a description of a system using mathematical concepts and language. The process of developing a mathematical model is termed mathematical modeling. Mathematical modeling in epidemiology provides understanding of the mechanisms that influence the spread of a disease and it suggests control strategies. One of the early triumphs of mathematical epidemiology was a formulation to predict the behavior of a disease. Mathematical models can project how infectious diseases progress to show the likely outcome of an epidemic and help inform public health interventions. Models use some basic assumptions and mathematics to find parameters for various infectious diseases and use those parameters to calculate the effects of possible interventions, like mass vaccination programs. The modeling of infectious diseases is a tool which has been used to study the mechanisms by which diseases spread, to predict the future course of an outbreak and to evaluate strategies to control an epidemic, [3].

The first scientist who systematically tried to quantify causes of death was John Graunt in his book "Natural and Political Observations" made upon the Bills of Mortality, in 1662.

The 1920s saw the emergence of compartmental models.
[9] described the relationship between susceptible, infected and immune individuals in a population. The model was successful in predicting the behavior of outbreaks very similar to that observed in many recorded epidemics, [2].

Mathematical models are of great importance in the natural sciences, particularly in physics. Physical theories are almost invariably expressed using mathematical models. Throughout history, more and more accurate mathematical models have been developed. Newton's laws accurately describe many everyday phenomena, but at certain limits relativity theory and quantum mechanics must be used; even these do not apply to all situations and need further refinement, [3].

It is common to use idealized models in physics to simplify things. Mass less ropes, point particles, ideal gases and the particle in a box are among the many simplified models used in physics. The laws of physics are represented with simple equations such as Newton's laws, Maxwell's equations and the Schrödinger equation, [4]. Often when engineers analyze a system to be controlled or optimized, they use a mathematical model, [4]. They can also help to identify where there may be problems or pressures, identify priorities and focus efforts. Where the mathematics results in equations that are too complex to solve directly, modelers 
have recourse to simulation. Other relevant papers consulted include the following: $[1,5-8,10,11]$.

\section{Model Formulation}

The total gender (host) population at time $\mathrm{t}$, denoted by $\mathrm{N}(\mathrm{t})$. The total population is partitioned into 5 mutually exclusive classes of Susceptible Individuals $\mathrm{S}(\mathrm{t})$, Infected Individuals in the early stage $I_{E}(t)$, Infected Individuals in the late stage $I_{L}(t)$, Treated Individuals who fail treatment $\mathrm{T}(\mathrm{t})$ and Treated Individuals who recovered from syphilis infection $\mathrm{R}(\mathrm{t})$.

Thus, the total population size $\mathrm{N}(\mathrm{t})$ can be determined by

$$
N(t)=S(t)+I_{E}(t)+I_{L}(t)+T(t)+R(t)
$$

The susceptible population (individuals) is (are) increased by the introduction or recruitment of new sexually active susceptible individuals into the population at a rate $\Lambda$. Through effective contact with infected individuals, i.e. individuals in the disease classes $\mathrm{I}_{\mathrm{E}}, \mathrm{I}_{\mathrm{L}}$ and $\mathrm{T}$, and susceptible individuals acquire the infection at a rate

$$
\lambda(t)=\frac{\phi}{N(t)}\left[I_{E}(t)+k I_{L}+\chi T(t)\right.
$$

where $\varphi=p \beta$

The term $\mathrm{P}$ represents the probability of transmitting syphilis infection per contact. The parameter $\beta$ is the average number of sexual partners. Therefore, $\varnothing$ is the effective contact rate for transmission of syphilis from one individual to the others. The modification parameters $\mathrm{K}$ and $\chi$, explains the assumed variability (i.e. increase and decrease) in the relative infectiousness of individuals in the $\mathrm{I}_{\mathrm{L}}$ and $\mathrm{T}$ classes respectively, in comparison to infected individuals in the $\mathrm{I}_{\mathrm{E}}$ class. Individuals in the $\mathrm{I}_{\mathrm{E}}$ class move forward to (i.e. they develop) the similar late stage $\left(\mathrm{I}_{\mathrm{L}}\right)$ of the infection at the rate $\pi$. Infected individuals are treated at the rate $\tau$. A fraction, $\omega$, of treated individuals from the early stage of infection will recover and move to the recovery (R) class, while the remaining fraction $(1-\omega)$, will fail treatment and move to the $T$ class. A fraction, $\eta$, of the treated individuals in the late stage of infection, will recover and move to the class $R$, while the remaining fraction, $(1-\eta)$ will fail treatment and move to the T class. Treated individuals who failed treatment of syphilis infection are induced to mortality. Recovered individuals are not re-infected at the rate $-\left(\theta^{*} \lambda\right)$ (with $\theta<0$ representing the non re-infection parameter).

In addition, natural mortality occurs in all epidemiological classes, except in recovered individuals at the rate $\mu$. Also, individuals in the $\mathrm{I}_{\mathrm{L}}$ class suffer additional diseases induced mortality at the rate $\rho$.

\subsection{Assumption of the Model}

We solve the model using Differential Transformation Method (DTM)

i. We assume one gender.

ii. For mathematical convenience, primary and secondary stages of infection are joined and referred to as "early stage of infection". Also, the latent and tertiary stages of infections are joined together as referred to as "late stage of infection".

iii. Infected individuals in both early and late stages can be treated.

iv. Treated infected individuals who failed treatment and infected individuals in both early and late stages are capable to transmit the disease.

v. Disease induced (brought about) death for treated individuals who failed treatment.

vi. There is no re-infection and disease relapse in recovered individuals. That means that immunity after recovery in permanent i.e. no loss of natural immunity.

\subsection{Parameters and Symbols}

The state variables and parameters of the model are tabulated in Table below.

\begin{tabular}{|c|c|}
\hline $\begin{array}{l}\text { Variables and } \\
\text { Symbols }\end{array}$ & Descriptions \\
\hline $\mathrm{S}$ & Susceptible individuals \\
\hline $\mathrm{I}_{\mathrm{E}}$ & Infected individuals in the early stage of infection \\
\hline $\mathrm{I}_{\mathrm{F}}$ & Infected individuals in the late stage of infection \\
\hline $\mathrm{T}$ & Treated individuals who recover from the infection \\
\hline $\mathrm{R}$ & Individuals who recovered from the infection \\
\hline$\Lambda$ & Recruitment rate of new sexually active individuals \\
\hline$\mu\left(\mathrm{S}, \mathrm{I}_{\mathrm{E}}, \mathrm{I}_{\mathrm{L}}, \mathrm{T}\right)$ & $\begin{array}{l}\text { Natural death rate(for susceptible, early and late } \\
\text { infectious, } T \text { and } R \text {. }\end{array}$ \\
\hline$\Pi$ & Progression rate from early to late stage of infection \\
\hline $\mathrm{T}$ & Treatment rate of disease \\
\hline$\alpha_{\mathrm{T}}$ & $\begin{array}{l}\text { Modification parameter for the variability in the treatment } \\
\text { rate of individuals in the late stage of infection, in } \\
\text { comparison to those in the early stage of infection }\end{array}$ \\
\hline$\Omega$ & $\begin{array}{l}\text { Proportion of treated individuals in the early stage who } \\
\text { recovered }\end{array}$ \\
\hline$\eta$ & $\begin{array}{l}\text { Proportion of treated individuals in the late stage who } \\
\text { recovered }\end{array}$ \\
\hline$\rho\left(I_{L}, T\right)$ & $\begin{array}{l}\text { Infection(disease)-induced death rate for individuals } \\
\text { who failed treatment }(T) \text { and those in } \mathrm{I}_{\mathrm{L}} \text { class }\end{array}$ \\
\hline$\Phi=\mathrm{p} \beta$ & Effective contact rate \\
\hline & Modification parameter for the assumed \\
\hline$\kappa$ & $\begin{array}{l}\text { variability(increase) in infectiousness of individuals in the } I_{L} \\
\text { class in comparison to infected individuals in the } I_{E} \text { class }\end{array}$ \\
\hline $\mathrm{X}$ & $\begin{array}{l}\text { Modification parameter for the assumed reduction } \\
\text { (decrease) in the relative infectiousness of individuals in } \\
\text { the } T \text { class, in comparison to infected individuals in } \\
\text { the } \mathrm{I}_{\mathrm{E}} \text { class }\end{array}$ \\
\hline$\lambda$ & Rate of syphilis infection \\
\hline $\mathrm{B}$ & Average number of sexual partners \\
\hline$\Theta$ & Re-infection rate \\
\hline $\mathrm{P}$ & Probability of transmitting syphilis infection \\
\hline$(1-\omega)$ & $\begin{array}{l}\text { Fraction of treated individuals from early stage of infection } \\
\text { who fail treatment and then moved to the T class }\end{array}$ \\
\hline$(1-\eta)$ & $\begin{array}{l}\text { Fraction of treated individuals in the late stage of } \\
\text { infection, who failed treatment }\end{array}$ \\
\hline $\mathrm{N}$ & Total population of individuals \\
\hline$\lambda(\mathrm{S}, \mathrm{R})$ & $\begin{array}{l}\text { Rate of syphilis infection by susceptible individuals, and } \\
\text { rate of syphilis recovery by treated individuals who } \\
\text { recover from the infection, respectively }\end{array}$ \\
\hline
\end{tabular}

Table 1. State Variables and Parameters.

\subsection{Schematic Diagram of the Model}

Below is the schematic diagram of the model 


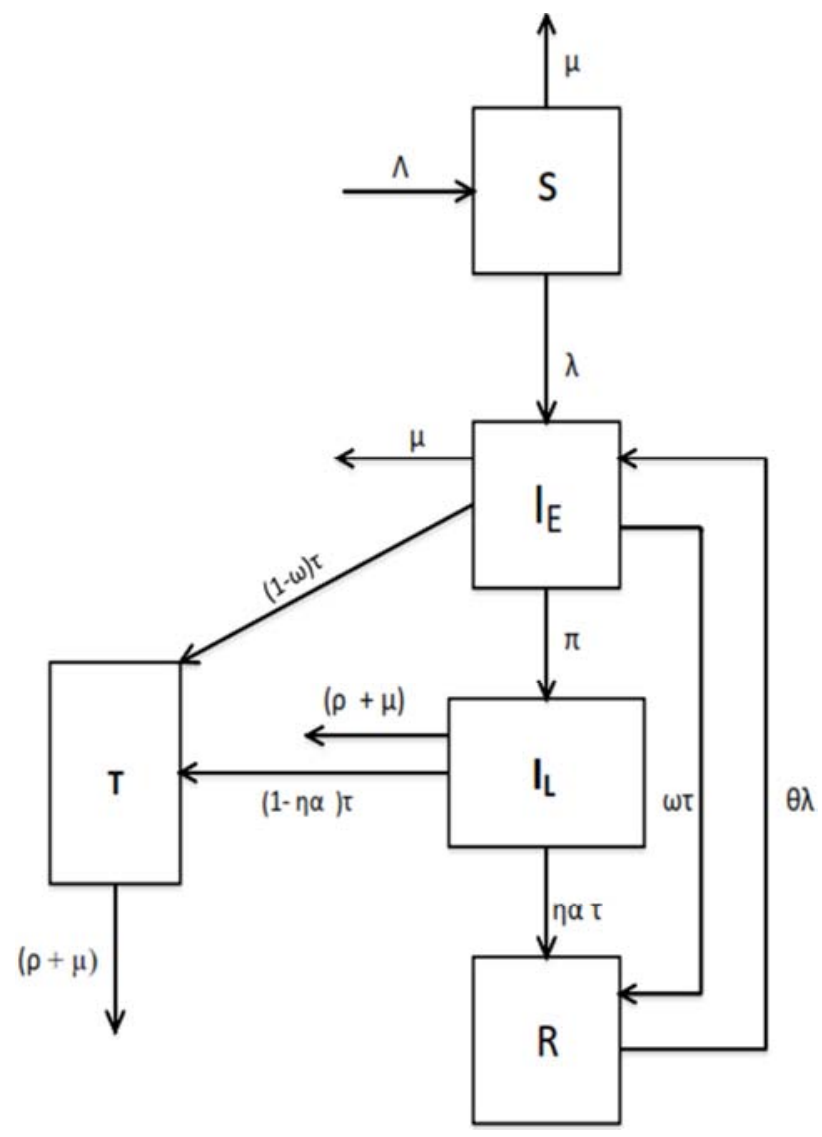

Figure 1. Schematic Diagram of the Model.

\subsection{The Model Equations}

Combining these definitions and assumptions, it follows that the model for the dynamic transmission of syphilis in a sexually active population is given by the following system of differential equations:

$$
\begin{aligned}
& \frac{d S}{d t}=\Lambda-(\lambda+\mu) S \\
& \frac{d I_{E}}{d t}=\lambda(S+\theta R)-(\pi+\omega \tau+\mu) I_{E} \\
& \frac{d I_{L}}{d t}=\pi I_{E}-(\eta \alpha \tau /=\rho+\mu) I_{L} \\
& \frac{d T}{d t}=(1-\omega) \tau I_{E}+(1-\eta \alpha) \tau I_{L}-(\rho+\mu) T \\
& \frac{d R}{d t}=\omega \tau I_{E}+\eta \alpha \tau I_{L}-\theta \lambda R
\end{aligned}
$$

\section{Methodology}

This section investigates the application of differential transformation method in finding the approximate solution of syphilis model. DTM uses the transformed function of the original nonlinear system. In this section, the model equation (1) is solved using the differential transformation method. Differential transformation method is a known technique used in solving linear and nonlinear equations. It was introduced by Zhou for solving linear and nonlinear initial value problems in electrical circuit analysis. The method has been used in solving differential algebraic equation, Schrödinger equations and fractional differential equation. The main advantage of this method is that it can be applied directly to linear and nonlinear ODEs without requiring linearization, discretization or perturbation. Another important advantage is that this method is capable of reducing the size of computational work while still accurately providing the series solution with fast convergence rate, Akinboro et al. (2014).

\subsection{The Differential Transformation Method}

An arbitrary function $f(x)$ can be expanded in Taylor series about a point $x=0$ as

$$
f(x)=\sum_{k=0}^{\infty} \frac{x^{k}}{k !}\left[\frac{d^{k} f}{d x^{k}}\right]_{x=0}
$$

The differential transformation of $f(x)$ is defined as

$$
F(x)=\frac{1}{k !}\left[\frac{d^{k} f}{d x^{k}}\right]_{x=0}
$$

Then the inverse differential transform is

$$
f(x)=\sum_{k=0}^{\infty} x^{k} F(k)
$$

The fundamental mathematical operations performed by differential transform method, are listed in Table 2.

Table 2. The fundamental operations of differential transformation method.

\begin{tabular}{ll}
\hline Original function & Transformed function \\
\hline $\mathrm{y}(\mathrm{x})=\mathrm{g}(\mathrm{x}) \pm \mathrm{h}(\mathrm{x})$ & $\mathrm{Y}(\mathrm{k})=\mathrm{G}(\mathrm{k}) \pm \mathrm{H}(\mathrm{k})$ \\
$\mathrm{y}(\mathrm{x})=\alpha \mathrm{g}(\mathrm{x})$ & $\mathrm{Y}(\mathrm{k})=\alpha \mathrm{G}(\mathrm{k})$ \\
$\mathrm{y}(\mathrm{x})=\frac{\mathrm{d}(\mathrm{x})}{\mathrm{dx}}$ & $\mathrm{Y}(\mathrm{k})=(\mathrm{k}+1) \mathrm{G}(\mathrm{k}+1)$ \\
$\mathrm{y}(\mathrm{x})=\frac{\mathrm{d}^{2} \mathrm{~g}(\mathrm{x})}{\mathrm{dx}^{2}}$ & $\mathrm{Y}(\mathrm{k})=(\mathrm{k}+1)(\mathrm{k}+2) \mathrm{G}(\mathrm{k}+2)$ \\
$\mathrm{y}(\mathrm{x})=\frac{\mathrm{d}^{\mathrm{m}} \mathrm{g}(\mathrm{x})}{\mathrm{dx}^{\mathrm{m}}}$ & $\mathrm{Y}(\mathrm{k})=(\mathrm{k}+1)(\mathrm{k}+2) \ldots(\mathrm{k}+\mathrm{m}) \mathrm{G}(\mathrm{k}+\mathrm{m})$ \\
$\mathrm{y}(\mathrm{x})=1$ & $\mathrm{Y}(\mathrm{k})=\delta(\mathrm{k})$ \\
$\mathrm{y}(\mathrm{x})=\mathrm{x}$ & $\mathrm{Y}(\mathrm{k})=\delta(\mathrm{k}-1)$ \\
$\mathrm{y}(\mathrm{x})=\mathrm{x}^{\mathrm{m}}$ & $\mathrm{Y}(\mathrm{k})=\delta(\mathrm{k}-\mathrm{m})=\left\{\begin{array}{l}1, k=m \\
0, k \neq m\end{array}\right.$ \\
$\mathrm{y}(\mathrm{x})=\mathrm{g}(\mathrm{x}) \mathrm{h}(\mathrm{x})$ & $\mathrm{Y}(\mathrm{k})=\sum_{m}^{k}=0 \mathrm{H}(\mathrm{m}) \mathrm{G}(\mathrm{k}-\mathrm{m})$ \\
$\mathrm{y}(\mathrm{x})=\mathrm{e}^{(\lambda \mathrm{x})}$ & $\mathrm{Y}(\mathrm{k})=\frac{\lambda^{k}}{k !}$ \\
$\mathrm{y}(\mathrm{x})=(1+\mathrm{x})^{\mathrm{m}}$ & $\mathrm{Y}(\mathrm{k})=\frac{\mathrm{m}(\mathrm{m}-1) \ldots(\mathrm{m}-\mathrm{k}+1)}{\mathrm{k} !}$ \\
\hline
\end{tabular}

\subsection{Application of Differential Transformation Method}

Using the transformed function of the original function in Table 1, we obtained the recurrence relation of equation (4) as

$$
(\mathrm{K}+1)=\frac{1}{\mathrm{~K}+1}\left[\Lambda-\sum_{\mathrm{m}=0}^{\mathrm{k}} \lambda(\mathrm{m}) \mathrm{S}(\mathrm{k}-\mathrm{m})-\mu \mathrm{S}(\mathrm{k})\right]
$$




$$
\begin{gathered}
\mathrm{I}_{\mathrm{E}}(\mathrm{K}+1)=\frac{1}{\mathrm{~K}+1}\left[\sum_{\mathrm{m}=0}^{\mathrm{k}} \lambda(\mathrm{m}) \mathrm{S}(\mathrm{k}-\mathrm{m})+\theta \sum_{\mathrm{m}=0}^{\mathrm{k}} \lambda(\mathrm{m}) \mathrm{R}(\mathrm{k}-\mathrm{m})-(\pi+\omega \tau+\mu) \mathrm{I}_{\mathrm{E}}(\mathrm{k})\right] \\
\mathrm{I}(\mathrm{K}+1)=\frac{1}{\mathrm{~K}+1}\left[\pi \mathrm{I}_{\mathrm{E}}(\mathrm{k})-(\eta \alpha \mu+\rho+\mu) \mathrm{I}_{\mathrm{L}}(\mathrm{k})\right] \\
\mathrm{T}(\mathrm{K}+1)=\frac{1}{\mathrm{~K}+1}\left[(1-\omega) \tau \mathrm{I}_{\mathrm{E}}(\mathrm{k})+(1-\eta \alpha) \tau \mathrm{I}_{\mathrm{L}(\mathrm{k})}-(\rho+\mu) \mathrm{T}(\mathrm{k})\right] \\
\mathrm{R}(\mathrm{K}+1)=\frac{1}{\mathrm{~K}+1}\left[\omega \tau \mathrm{I}_{\mathrm{E}}(\mathrm{k})+\eta \alpha \tau \mathrm{I}_{\mathrm{L}}(\mathrm{k})-\theta \sum_{\mathrm{m}=0}^{\mathrm{k}} \lambda(\mathrm{m}) \mathrm{R}(\mathrm{k}-\mathrm{m})\right]
\end{gathered}
$$

With assumed initial conditions $\mathrm{s}(0)=1000, \mathrm{i}_{\mathrm{E}}(0)=200$, $\mathrm{i}_{\mathrm{L}}(0)=200, \mathrm{t}(0)=200, \mathrm{r}(0)=10$ and parameters $\Lambda=$ $1020.3, \mu=0.0000548, \theta=0.9, \mathrm{k}=1.2, \chi=0.5, \pi=0.04762$, $\tau=0.36, \alpha=0.25, \rho=0.06849, \omega=0.9, \eta=0.9, \varnothing=(\mathrm{p} \beta)=$ 0.3 , then $\mathrm{S}(0)=1000, \mathrm{I}_{\mathrm{E}}(0)=200, \mathrm{I}_{\mathrm{L}}(0)=200, \mathrm{~T}(0)=200$,

$$
\begin{gathered}
\mathrm{S}(1)=919.50, \mathrm{~S}(2)=466.30, \mathrm{~S}(3)=328.90, \mathrm{~S}(4)=243.37, \mathrm{~S}(5)=197.04, \ldots, \mathrm{I}_{\mathrm{E}}(2)=47.3, \mathrm{I}_{\mathrm{E}}(3)=14.42, \mathrm{I}_{\mathrm{E}}(4)=9.74, \mathrm{I}_{\mathrm{E}}(5)=6.31, \ldots, \\
\mathrm{I}_{\mathrm{L}}(1)=-20.4, \mathrm{I}_{\mathrm{L}}(2)=2.2, \mathrm{I}_{\mathrm{L}}(3)=0.64, \mathrm{I}_{\mathrm{L}}(4)=0.15, \mathrm{I}_{\mathrm{L}}(5)=0.88, \ldots, \\
\mathrm{T}(1)=49.3, \mathrm{~T}(2)=-4.10, \mathrm{~T}(3)=0.87, \mathrm{~T}(4)=0.16, \mathrm{~T}(5)=0.08, \ldots, \\
\mathrm{R}(1)=80, \mathrm{R}(2)=-0.091 \mathrm{R}(3)=4.75, \mathrm{R}(4)=1.46, \mathrm{R}(5)=0.56, \ldots,
\end{gathered}
$$

Then, the closed form of the solution where $\mathrm{k}=4$ can be written as;

$$
\begin{aligned}
& \mathrm{s}(\mathrm{t})=\sum_{\mathrm{m}=0}^{\mathrm{k}} \mathrm{S}(\mathrm{t}) \mathrm{t}^{\mathrm{k}}=\mathrm{S}(0) \mathrm{t}^{0}+\mathrm{S}(1) \mathrm{t}^{1}+\mathrm{S}(2) \mathrm{t}^{2}+\mathrm{S}(3) \mathrm{t}^{3}+\mathrm{S}(4) \mathrm{t}^{4}+\mathrm{S}(5) \mathrm{t}^{5}+\cdots \\
& s(t)=1000+919.5 t+466.3 \mathrm{t}^{2}+328.9 \mathrm{t}^{3}+243.37 \mathrm{t}^{4}+197.04 \mathrm{t}^{5}+\cdots \\
& \mathrm{i}_{\mathrm{E}}(\mathrm{t})=\sum_{\mathrm{m}=0}^{\mathrm{k}} \mathrm{I}_{\mathrm{E}}(\mathrm{k}) \mathrm{t}^{\mathrm{k}}=\mathrm{I}_{\mathrm{E}}(0) \mathrm{t}^{0}+\mathrm{I}_{\mathrm{E}}(1) \mathrm{t}^{1}+\mathrm{I}_{\mathrm{E}}(2) \mathrm{t}^{2}+\mathrm{I}_{\mathrm{E}}(3) \mathrm{t}^{3}+\mathrm{I}_{\mathrm{E}}(4) \mathrm{t}^{4}+\mathrm{I}_{\mathrm{E}}(5) \mathrm{t}^{5}+\cdots \\
& i(t)=200+27 t+47.3 t^{2}+14.42 t^{3}+9.74 t^{4}+6.31 t^{5}+\cdots \\
& \mathrm{i}_{\mathrm{L}}(\mathrm{t})=\sum_{\mathrm{m}=0}^{\mathrm{k}} \mathrm{I}_{\mathrm{L}}(\mathrm{k}) \mathrm{t}^{\mathrm{k}}=\mathrm{I}_{\mathrm{L}}(0) \mathrm{t}^{0}+\mathrm{I}_{\mathrm{L}}(1) \mathrm{t}^{1}+\mathrm{I}_{\mathrm{L}}(2) \mathrm{t}^{2}+\mathrm{I}_{\mathrm{L}}(3) \mathrm{t}^{3}+\mathrm{I}_{\mathrm{L}}(4) \mathrm{t}^{4}+\mathrm{I}_{\mathrm{L}}(5) \mathrm{t}^{5}+\cdots \\
& \mathrm{i}_{\mathrm{L}}(t)=200-20.4 \mathrm{t}+2.2 \mathrm{t}^{2}+0.64 \mathrm{t}^{3}+0.15 \mathrm{t}^{4}+0.88 \mathrm{t}^{5}+\cdots \\
& \mathrm{t}(\mathrm{t})=\sum_{\mathrm{m}=0}^{\mathrm{k}} \mathrm{T}(\mathrm{k}) \mathrm{t}^{\mathrm{k}}=\mathrm{T}(0) \mathrm{t}^{0}+\mathrm{T}(1) \mathrm{t}^{1} \mathrm{~T}(2) \mathrm{t}^{2}+\mathrm{T}(3) \mathrm{t}^{3}+\mathrm{T}(4) \mathrm{t}^{4}+\mathrm{T}(5) \mathrm{t}^{5}+\cdots \\
& t(t)=200+49.3 t-4.10 t^{2}+0.87 t^{3}+0.16 t^{4}+0.08 t^{5}+\cdots \\
& \mathrm{r}(\mathrm{t})=\sum_{\mathrm{m}=0}^{\mathrm{k}} \mathrm{R}(\mathrm{k}) \mathrm{t}^{\mathrm{k}}=\mathrm{R}(0) \mathrm{t}^{0}+\mathrm{R}(1) \mathrm{t}^{1}+\mathrm{R}(2) \mathrm{t}^{2}+\mathrm{R}(3) \mathrm{t}^{3}+\mathrm{R}(4) \mathrm{t}^{4}+\mathrm{R}(5) \mathrm{t}^{5}+\cdots \\
& r(t)=10+80 t-0.091 t^{2}+4.75 t^{3}+1.46 t^{4}+0.56 t^{5}+\cdots
\end{aligned}
$$

\section{Mathematical Analysis of the Model}

The analysis of the model (1) complements the transmission dynamic of syphilis diseases in the literature of Gumel et al. by, inter alia

i. considering only one gender as the total population

ii. solving the model using Differential Transformation
Method (DTM), and iii. non re-infection or disease relapse in recovered individuals.

\subsection{Local Asymptotic Stability of Disease-Free Equilibrium (DFE)}

The disease-free-equilibrium (DFE), $\varepsilon_{0}$, of the model (2.1) 
at $\mathrm{I}_{\mathrm{E}}=\mathrm{I}_{\mathrm{L}}=\mathrm{T}=0$, is given by

$$
\operatorname{DFE}=\left(\mathrm{S}^{*}, \mathrm{I}_{\mathrm{E}}^{*}, \mathrm{I}_{\mathrm{L}}^{*}, \mathrm{~T}, \mathrm{R}\right)=\left(\frac{\Lambda}{\mu}, 0,0,0,0\right) .
$$

The non negative matrix, $\mathrm{F}$, of the new infection terms and the inverse matrix of $\mathrm{V}$, of transition terms associated with the model are given below

$$
\mathrm{F}=\left[\begin{array}{ccc}
\varnothing & \emptyset \kappa & \emptyset \chi \\
0 & 0 & 0 \\
0 & 0 & 0
\end{array}\right] \text { and } \mathrm{V}=\left[\begin{array}{ccc}
\mathrm{k}_{1} & 0 & 0 \\
-\pi & \mathrm{k}_{2} & 0 \\
-\mathrm{G}_{1} & -\mathrm{G}_{2} & \mathrm{~m}
\end{array}\right]
$$

where

$$
\begin{gathered}
\mathrm{k}_{1}=-(\pi+\omega \tau+\mu), \mathrm{k}_{2}=-(\eta \alpha \tau+\rho+\mu), \mathrm{m}= \\
-(\rho+\mu), \mathrm{G}_{1}=(1-\omega) \tau, \mathrm{G}_{2}=(1-\eta) \alpha_{\mathrm{T}} \tau \text { and } \varphi=\mathrm{p} \beta
\end{gathered}
$$

$$
V^{-1}=\left[\begin{array}{ccc}
\frac{1}{\mathrm{k}_{1}} & 0 & 0 \\
\frac{\pi}{\mathrm{k}_{1} \mathrm{k}_{2}} & \frac{1}{\mathrm{k}_{2}} & 0 \\
\frac{\pi \mathrm{G}_{2}+\mathrm{k}_{2} \mathrm{G}_{1}}{\mathrm{mk}_{1} \mathrm{k}_{2}} & \frac{\mathrm{G}_{2}}{\mathrm{mk}_{2}} & \frac{1}{\mathrm{~m}}
\end{array}\right]
$$

The basic reproduction number of the model (2.1), denoted by $\mathrm{R}_{0}=\left(\mathrm{FV}^{-1}\right)$, is given by

$$
R_{o}=\frac{\phi}{k_{1}}\left(1-\frac{k \pi}{k_{2}}+\frac{\chi \pi G_{2}+\chi k_{2} G_{1}}{m k_{2}}\right)
$$

In particular, the threshold quantity $R_{0}$ measures and represents the average number of new syphilis infections in a population generated by a single infected individual introduced into a completely susceptible population. It is the geometric mean of the reproduction numbers for individuals. This implies that syphilis can be effectively controlled in (or eliminated from) the community (when $\mathrm{R}_{0}<1$ ) if the initial sizes of the subpopulations of the model are in the basin of attraction of the DFE $\left(\mathrm{R}_{0}\right)$. To ensure that disease elimination is independent of the initial sizes of the subpopulations, it is necessary to show that the DFE is globally asymptotically stable if $\mathrm{R}_{0}<1$.

\subsection{Sensitivity Analysis}

The asymptotic analysis of most epidemiological models has dependably been based on the threshold quantity called the basic reproduction number, which can lead to uncertainties particularly when the model consists of many parameters. Another reason for uncertainties in these models is the absence of precision in the estimation of all associated parameters, error in collecting and interpreting data and natural variations. Thus, to determine the impact of the model parameters on the transmission dynamics of the syphilis, a sensitivity analysis will be conducted using Latin hypercube sampling (Left Hand Side (LHS)).

Left hand side is a statistical method for generating a sample of plausible collections of parameter values from a multidimensional distribution. Using the range of plausible values for the 12 parameters of the model (3) (see Table 1 for the mean and associated distributions of these parameters), a sample of size $\mathrm{N}=1610$ is obtained through LHS. LHS treats the model inputs (i.e. the model parameters), as random variables. Thus, appropriate probability distributions will be associated with each parameter. The analysis below assumes that the model inputs can take the form of uniform, gamma, or normal distributions. The LHS (left hand side) procedure is implemented by dividing the range of values for each given parameter into equally probable, intervals and one selected at random from each interval with the objective of uniformly filling the input space.

Table 3. Mean values of the model parameters with their assigned distributions.

\begin{tabular}{lllll}
\hline Parameters & Distribution & Range & Baseline Values & References \\
\hline$\mu$ & Normal & $5.08 \times 10^{-5}-5.89 \times 10^{-5}$ & $5.48 \times 10^{-5}$ day $^{-1}$ & World Bank \\
$\pi$ & Normal & $3.89 \times 10^{-2}-5.73 \times 10^{-2}$ & $4.762 \times 10^{-2}$ day $^{-1}$ & Garnett et al $^{-1}$ \\
$\tau$ & Normal & $2.75 \times 10^{-1}-4.51 \times 10^{-1}$ & $3.6 \times 10^{-1}$ day $^{-1}$ & Garnett et al \\
$\eta$ & Normal & $1.99 \times 10^{-2}-1.79 \times 10^{-1}$ & 0.9 & Assumed \\
$\varphi$ & Gamma & $8.5 \times 10^{-1}-9.5 \times 10^{-1}$ & 0.3 & Assumed \\
$\omega$ & Normal & $8.5 \times 10^{-1}-9.5 \times 10^{-1}$ & 0.9 & Assumed \\
$\rho$ & Normal & $5.8 \times 10^{-2}-7.68 \times 10^{-2}$ & $6.849 \times 10^{-2}$ day $^{-1}$ & Iboi and Okuonghae \\
$\alpha_{T}$ & Normal & $2.35 \times 10^{-2}-4.49 \times 10^{-1}$ & 0.25 & Garnett et al \\
$\phi$ & Gamma & $1.86 \times 10^{-1}-4.54 \times 10^{-1}$ & 0.3 & Garnett et al \\
$\kappa$ & Gamma & $1-1.4$ & 1.2 & Assumed \\
$\chi$ & Gamma & $3.15 \times 10^{-1}-7.39 \times 10^{-1}$ & 0.5 & Assumed \\
$\Lambda$ & - & - & $1.020 \times 10^{3}$ day $^{-1}$ & World Bank \\
$\theta$ & - & - & 0.9 & Assumed \\
\hline
\end{tabular}

The sign indicates the qualitative relationship between the parameter inputs and $\mathrm{R}_{0}$. A negative sign indicates that the LHS parameter is inversely proportional to the $\mathrm{R}_{0}$.

The analysis is completed using parameter values relevant to syphilis transmission dynamics in Nigeria, given in Table 3 . The distribution of the mean value of $\mathrm{R}_{0}$ as a function of distributions of various parameters of the model reveals that the estimate of $R_{0}$ for syphilis is approximately-1.43, which is less than unity. The probability that $\mathrm{R}_{0}>1$ for syphilis is given by 1 . Hence, under the assumed conditions, syphilis will become endemic in the population. Results from the sensitivity analyses of the model, using $\mathrm{R}_{0}$ as the response function, shows that the dominant parameters of the model, are effective contact rate for individuals $(\phi=\mathrm{p} \beta)$, proportion of treated individuals in the early stage who recovered from the disease $(\omega)$, the modification parameter for the assumed decrease in the recovery rate of individuals in the $\mathrm{T}$ class, in comparison to successfully treated individuals $\left(\alpha_{T}\right)$. The 
implication of these analyses is that effective communitywide control of the disease can be achieved by minimizing the contact rates and $\kappa$ (perhaps by implementing an effective public health education campaign to encourage safer sex practices within the sexually active population), early detection and treatment of infected individuals (this can be achieved by devoting resources to monitoring infected

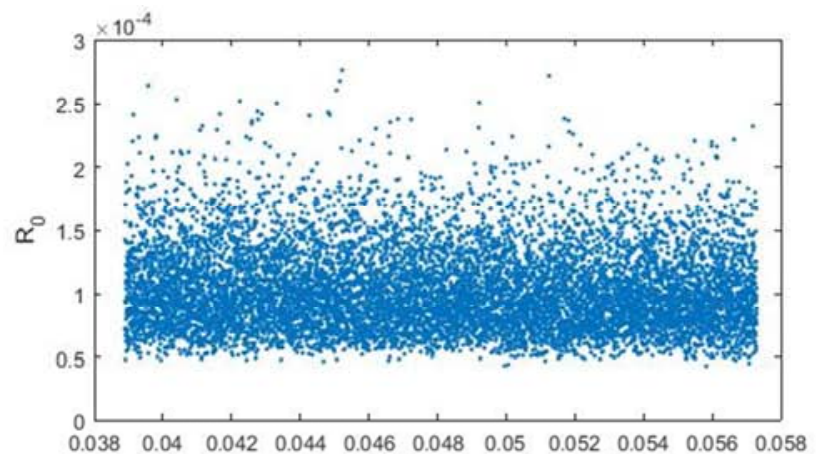

$\mu$
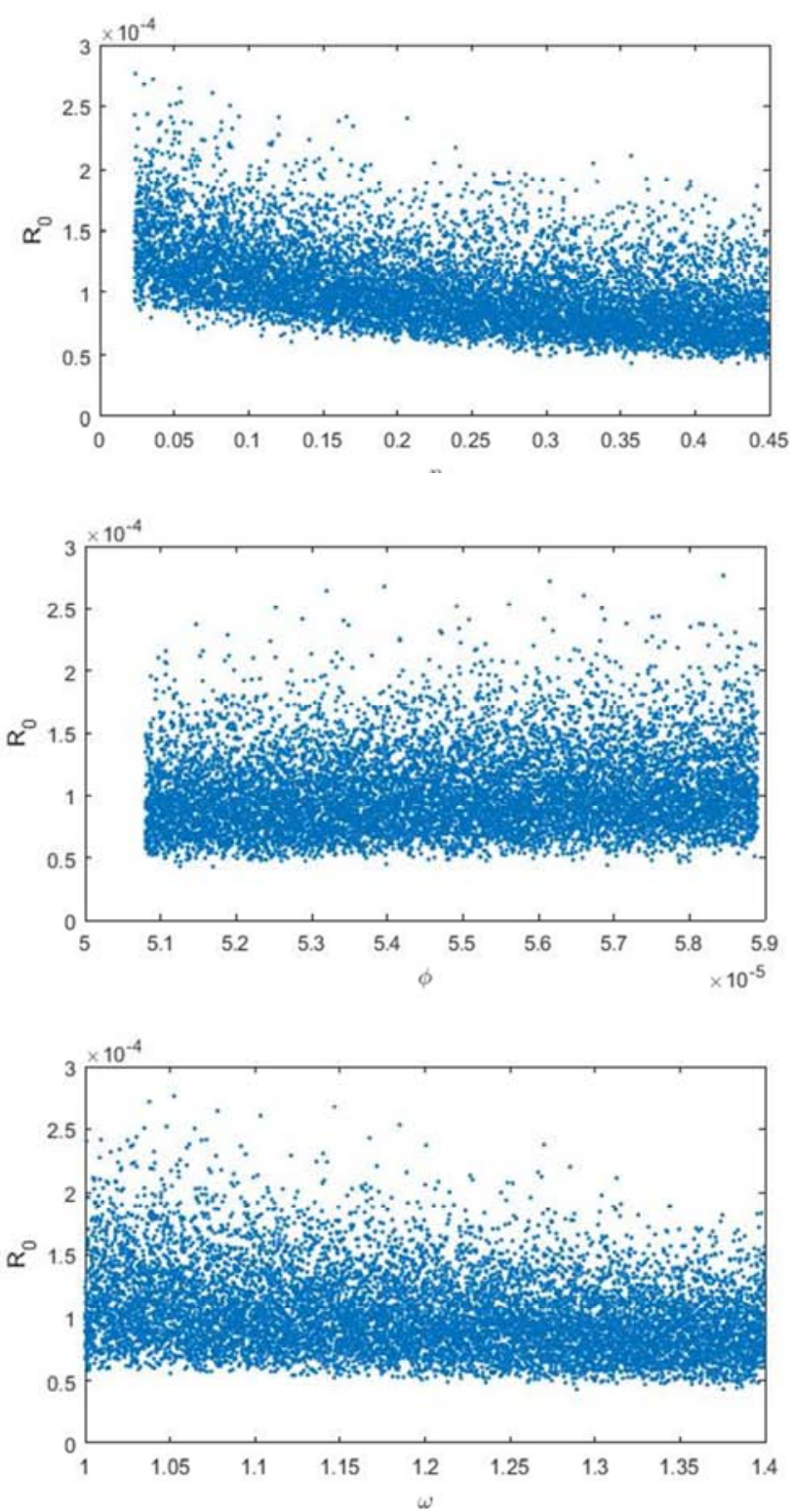

individuals via contact tracing), and increase the recovery rate of individuals who failed treatment (by, perhaps, using better drugs and encouraging treated individuals to adhere to the prescribed treatment regimen). Thus, this study identifies key parameters that should be targeted for the design of effective public health strategy or policy for combating the spread of syphilis in the community.
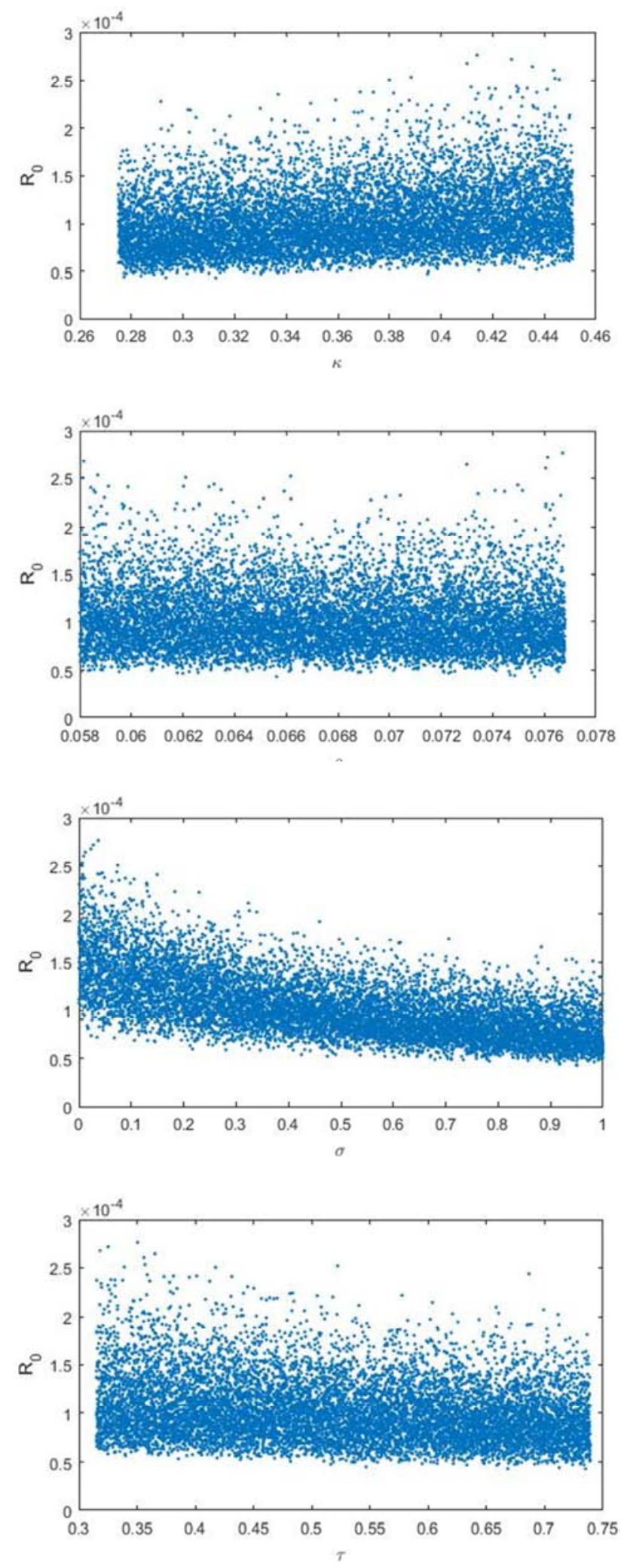

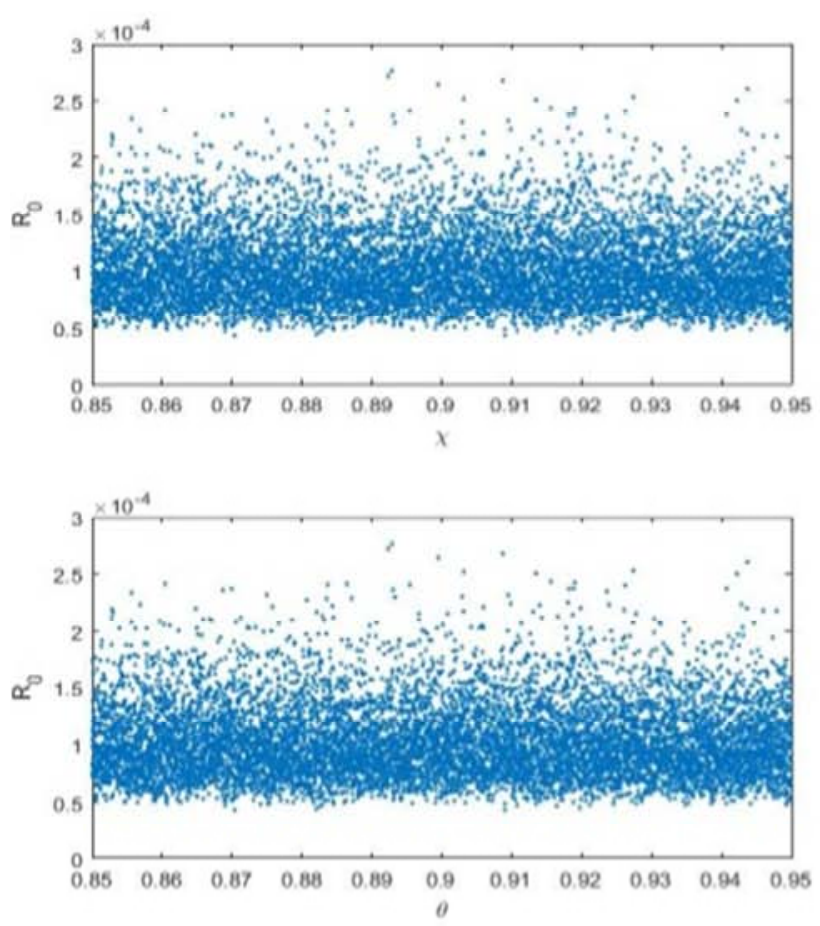

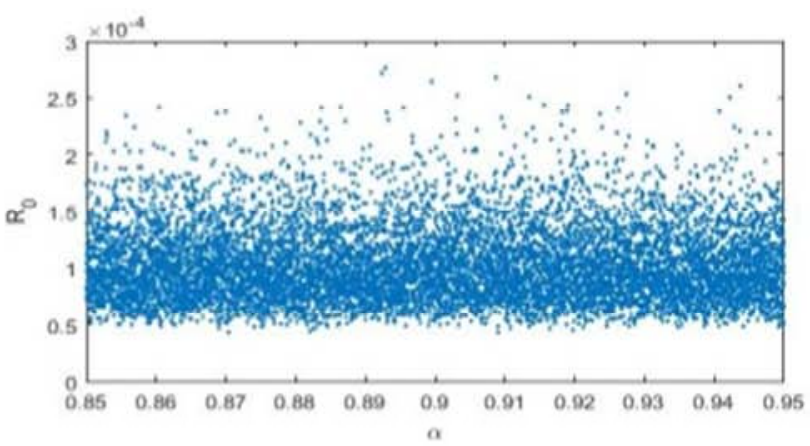

Figure 2. Graphs of sensitivity analysis showing the parameters varying the basic reproduction number.

\section{Summary, Conclusion and Recommendations}

\subsection{Summary}

Syphilis is one of the most-deadly sexually transmitted diseases. Every year, it accounts for over 12 million cases and over 200,000 fatalities globally (inflicting major public health burden in both developing and developed countries of the world). Control against syphilis includes; rapid diagnosis of suspected cases and treatment of confirmed cases.

This study presents a new deterministic model for gaining insight into the transmission dynamics of syphilis in a population. In addition to allowing for the assessment of the population-level impact of treatment strategies the model includes some pertinent features of the disease, such as the multiple stages of infection in untreated patients (represented by "early" and "late" stage of infection) and not allowing for re-infection of, and disease relapse from, recovered individuals.

Thus, for the case when re-infection of recovered individuals is small enough, the implementation of the control strategy is adopted (treatment of confirmed cases) can lead to the effective control (or elimination) of the disease from the community if they can result in bringing (and maintaining) the associated reproduction number of the model to a value less than unity. Thus, this study suggests that the prospects of the effective control of syphilis in a population, using treatment is promising.

The model developed in this study consists of numerous parameters, and uncertainties were expected to exist in the estimate of their values used in the numerical simulations of the model. The effect of such uncertainties (on the simulation results obtained) was assessed using LHS, with the reproduction number of the model as the response function. In other words, more needs to be done in terms of increasing rapid diagnosis and treatment of confirmed cases and public health education and counselling to encourage safer sex practices.

Detailed sensitivity analysis of the model shows that the most important parameters that affect the reproduction number of the model (hence, disease burden) are the proportion of treated individuals in the early stage who recovered and the modification parameter associated with the decrease in recovery rate for individuals who failed treatment. This suggests (as expected) that increasing recovery rate of those who failed treatment will decrease syphilis burden in the community.

\subsection{Conclusion}

This study suggests that the effective control of syphilis in a population, using treatment is promising.

Therefore more needs are to be done in terms of increasing rapid diagnosis, treatment of confirmed cases, public health education and counselling to encourage safer sex practices.

Also suggests (as expected) that increasing recovery rate of those who failed treatment will decrease syphilis burden in the community.

\subsection{Recommendations}

For effective control of syphilis in susceptible population, it is recommended that the basic reproduction number to be less than unity by using treatment strategies such as monitoring the rate of contact and the proportion of treated 
individuals in early and late stage who recovered, vaccination, taking rapid diagnosis of cases of susceptible individuals in the population and increasing the recovering rate of treated individuals in the population too. Also, it is pertinent to use control strategies such as the public health education and counselling to encourage safer sex practices in population.

\section{References}

[1] Akinboro F. S., Alao S. and Akinpelu F. O. (2014) Numerical Solution of SIR Model using Differential Transformation Method and Variational Iteration Method. Vol. 22. Pg 82-92.

[2] Aris S. and Ivey R. M. S. (2004) Principles of Mathematical Modeling; 1st Edition, Academic Press, New York.

[3] Brauer F. and Castillo-Chavez C. (2001) Mathematical Models in Population Biology and Epidemiology the Amerian Mathematical Monthly 40: 267-291.

[4] Dym C. L. and Ivey E. S. (2002) Principles of Mathematical Modeling, 1st Edition, Academic Press, New York.

[5] Garnett G. P., Aral S. O., Hoyle D. V., Cates W. and Anderson
R. M. (1997) The natural history of syphilis: implications for the transition dynamics and control of infection. Sex Transm Dis. Vol. IV. Pp 185-200.

[6] Gumel A. B., Jean M. S., Oluwaseun S., Yibeltal A. T. (2017). Mathematics of a sex-structured model for syphilis transmission dynamics.

[7] Iboi E. and Okuonghae D. (2016) Population Dynamics of a Mathematical model for syphilis. Appl Math Modeling, Vol. IV, Pp. 3573-3590.

[8] Kermack, W. O and McKendrick, A. G (1927). A Contribution to the Mathematical Theory of Epidemics, Proceedings of the Royal Society Vol. 115, No. 772, pp. 700721.

[9] Kiarie J., Mishra C. K., Temmerman M. and Newman L. (2015) Accelerating the dual elimination of mother-to-child transmission of syphilis and HIV: why now?, International Journal of Gynecology Obstetrics; Vol. I, Pp. 130.

[10] World Bank Life expectancy at birth data.worldbank.org; Accessed 12 May 2018.

[11] World Health Report, the world health report 2004-changing history. http://www.who.int/whr/2004/en/, Assessed June 28, 2018. 